\title{
Developmental morphology of mouthparts and foregut of the larvae and postlarvae of Lepidophthalmus siriboia Felder \& Rodrigues, 1993 (Decapoda: Callianassidae)
}

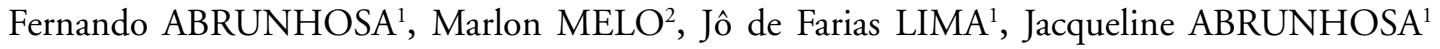

\section{ABSTRACT}

In this study, the gross morphology of the mouthparts and foregut of the ghost shrimp Lepidophthalmus siriboia were investigated from larvae and postlarvae reared in the laboratory. The mouthparts (maxillae and maxillipeds) of the zoeae have a reduced number of setae and spines (or is absent in some individuals), and the foregut, under developed, have few minute setae in the cardiac and pyloric chambers. In contrast, after the metamorphosis into megalopa stage, all feeding appendages have many setae and, the foregut shows a well-developed gastric mill with strong lateral teeth. In the juvenile stage occurs an increase of setae and spines in the mouthparts and the foregut becomes more specialized. These observations strongly suggest that a lecithotrophic development occurs during all zoeal stages but the megalopa and juvenile stages are feeding animals. The functional morphology of the feeding structures of $L$. siriboia and other decapods will be briefly discussed.

\section{KEYWORDS}

Callianassidae, Lepidophthalmus siriboia, mouthparts, foregut, morphology.

\section{Morfologia funcional dos apêndices bucais e do estômago de larvas e pós- larvas de Lepidophthalmus siriboia Felder \& Rodrigues, 1993 (Decapoda: Callianassidae)}

\begin{abstract}
RESUMO
A morfologia dos apêndices bucais e o estômago de larvas e pós-larvas de Lepidophthalmus siriboia cultivados em laboratório foi investigada. Os apêndices bucais (maxilas e maxilipedes) durante os estágios zoeae apresentam número reduzido de cerdas e espinhos, ou mesmo, ausentes em alguns indivíduos. O estômago aparece pouco desenvolvido, com poucas cerdas pequenas nas câmaras cardíaca epilórica. Contrariamente, após a metamorfose para o estágio megalopa, todas estas estruturas bucais possuem muitas cerdas, e o estômago apresenta um moinho gástrico bem desenvolvido com dois fortes dentes laterais. No estágio juvenil ocorre incremento de cerdas e espinhos em todas estruturas bucais e o estômago torna-se mais especializado. Estas observaçôes sugerem fortemente que as zoeae de L. siriboia têm desenvolvimento lecitotrófico, mas que as megalopae e juvenis passam a ingerir alimentos exógenos.
\end{abstract}

PALAVRAS-CHAVES

Callianassidae, Lepidophthalmus siriboia, apêndices bucais, estômago, morfologia.

\footnotetext{
1 Universidade Federal do Pará, Núcleo de Estudos Costeiros, Alameda Leandro Ribeiro, Bairro: Aldeia, 68.600-000. Bragança - PA - Brasil, e-mail - faraujo@ufpa.br, jflima@yahoo.com.br, jpabrunhosa@yahoo.com.br

2Universidade Federal do Ceará, Mestrado em Engenharia de Pesca, Campus do Pici, Bairro: Pici, 60.356-000. Fortaleza -CE - Brasil, e-mail - aguiarmarlon@hotmail.com
} 


\section{INTRODUCTION}

Food is considered critical for the successful culture of decapod larvae. However, the addition of food in tanks may sometimes be unnecessary because some larvae are sufficiently lecithotrophic to complete some stages or even the complete larval development without external food (Kittaka, 1988; Nishida et al., 1990; Kittaka, 1994; Anger et al. 1995; Abrunhosa and Kittaka, 1997a,b; Nates and McKenney Jr, 2000). Some species, however, may present a facultative lecithotrophy if external food is not available in the environment (Anger et al., 1995; Thessalou-Legaki et al., 1999).

Unfortunately, feeding behavior in decapod larva is not frequently reported in the scientific literature, mainly in those species in which have not economical values. Most studies on lecithotrophic behavior of decapod larvae concentrate on the survival rates, larval density, etc.. However, feeding experiments in crustacean or observations of the external and internal feeding structures have contributed to clarify feeding or non-feeding larval behavior (Nishida et al., 1990; Abrunhosa and Kittaka, 1997a,b; Anger et al., 1995).

Several studies were reported showing non-feeding behavior in the transitional metamorphic stage in pueruli of spiny lobster (Kittaka, 1988; Nishida et al., 1990; Kittaka, 1994; Lemmens and Knott, 1994; Nishida et al., 1995) and megalopa king crab Paralithodes (Abrunhosa and Kittaka, 1997a, b).

Detailed morphological studies on the digestive system of decapod larvae have demonstrated that a close relationship occurs between the morphological characteristic of the digestive system and larval feeding behavior (Nishida et al., 1990; Abrunhosa and Kittaka, 1997a). The authors reported that pueruli of spiny lobster and glaucothoe of king crabs are non-feeding larval stage because they have shown under developed and uncalcified feeding appendages and foregut (Wolfe and Felgenhauer, 1991; Kittaka, 1994; Lemmens and Knott, 1994; Nishida et al., 1995; Abrunhosa and Kittaka, 1997b).

The present study aims to describe the gross morphology of the external feeding appendages and foregut during the development from larvae to the postlarvae stages of the callianassid L. siriboia.

\section{MATERIAL AND METHODS}

The morphological features of external mouthparts and foregut of $L$. siriboia were examined from samples of larvae and post larvae obtained from a larval culture for complete larval description carried out in the State of Pará in 2004 by Abrunhosa et al. (2005).

The larvae were preserved in glycerol + ethylic alcohol $70 \%$ solution after each molting. At least 10 individuals for each stage were dissected and they were used in the illustrations. The foreguts were examined from individuals of the zoeae, megalopa and juvenile I fixed in 10\% formalin solution buffered with sodium phosphate. The foreguts were observed from 10 individuals of each stage immersed in $20 \mathrm{~mL}$ of $5 \%$ aqueous solution of $\mathrm{KOH}$ heated to $80^{\circ} \mathrm{C}$ for about 1 hour. Then, the samples were washed and preserved in ethylic alcohol $70 \%+$ glycerin solution $(1: 1)$. The foreguts were dissected and stained with methylene blue $1 \%$ solution. The terminology used for the description of the foregut follows Meiss and Norman (1977), Nishida et al. (1990), Abrunhosa and Kittaka (1997a) and Abrunhosa et al. (2003).

\section{RESULTS}

\section{MORPHOLOGY OF THE MOUTHPARTS}

\section{Zoea I}

Maxillule (Fig.1a) - Coxal and basal endites lacking setae, bearing small marginal spines; endopod unsegmented, lacking setae.

Maxilla (Fig. 1b) - Basal and coxal endites bilobed, lacking setae; endopod unsegmented, lacking setae; scaphognathite with 3-4 setae marginal on anterior and 2 setae on posterior margins.

First maxilliped (Fig.2a) - Basipod lacking setae or showing a row of minute marginal setae; endopod incompletely 2segmented with 2-3 distal setae; exopod with 4 plumose setae.

Second maxilliped (Fig.2b) - Basipod lacking setae; endopod 4-segmented with $1+1$ setae on the distal segment; exopod with 4 plumose setae.

Third maxilliped (Fig.2c) - Basipod lacking setae; endopod 4-segmented with $2+1$ setae on distal segment; exopod with 5 plumose setae.
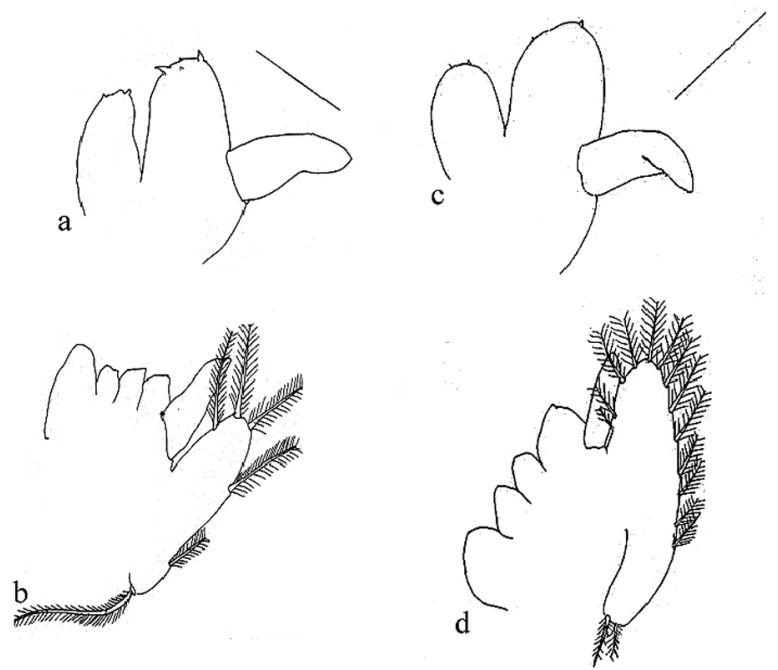

Figure 1 - Mouthparts of Lepidophtalmus siriboia, Felder \& Rodrigues, 1993. Zoea I, a-b; c-d, zoea III. a-maxillule, b-maxilla;. c-maxillule, d-maxilla. Scale bar: $a, b=0.07 \mathrm{~mm} ; c, d=0.1 \mathrm{~mm}$. 

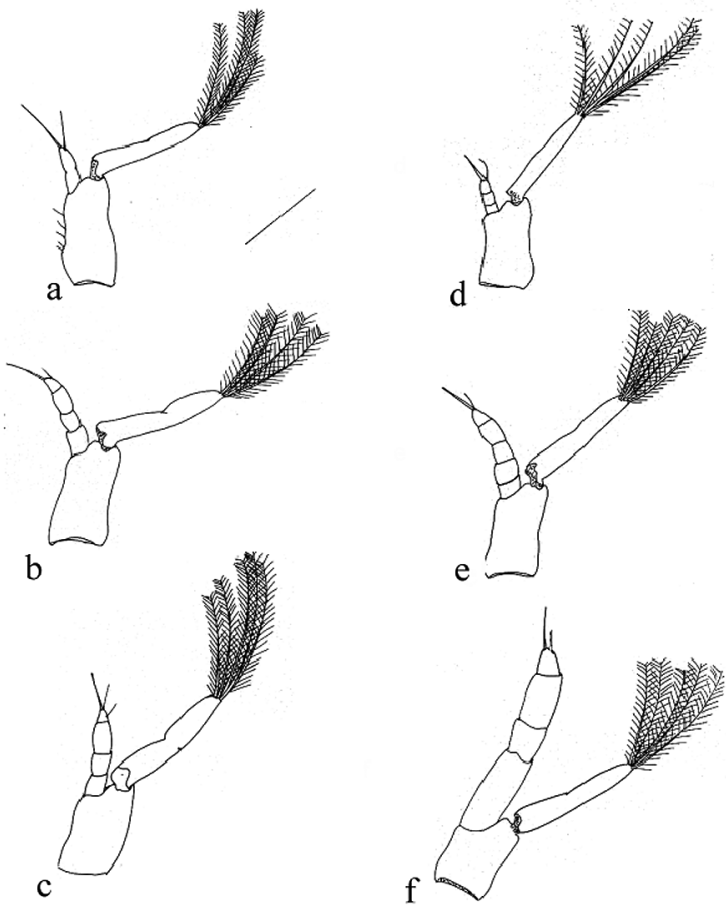

Figure 2 - Mouthparts of Lepidophtalmus siriboia, Felder \& Rodrigues, 1993. a-c, Zoea I; d-f, Zoea III. a - Maxilliped I, b - Maxilliped II, c Maxilliped III; $d$ - Maxilliped I, e - Maxilliped II, $f$ - Maxilliped III. Scale bar: $0.3 \mathrm{~mm}$.

ZOEA II - Without noteworthy changes.

\section{ZOEA III (Last zoeal stage)}

Maxillule (Fig.1c) - Similar to the previous stages.

Maxilla (Fig.1d) -Endopod similar to the previous stages; scaphognathite with (12-13)+2 plumose setae.

First maxilliped (Fig.2d) - Basipod with row of simple setae; endopod 3-segmented with 2 distal setae; exopod with 5 plumose setae.

Second maxilliped (Fig.2e) - Endopod similar to zoea I in seta number but 5 -segmented; exopod with 5 plumose setae.

Third maxilliped (Fig.2f) - Similar to the previous stages.

\section{MEGALOPA}

Maxillule (Fig.3a) - Coxal endite with 9-14 marginal setae; basal endite with 11 marginal spines and 6 setae; endopod lacking setae.

Maxilla (Fig.3b) - Coxal endite trilobed, distal lobe with $12+7$ setae; proximal lobe with 5 setae; distal and proximal lobes of basal endite bearing 10 and 6 setae, respectively; endopod with $1+3$ simple setae; scaphognathite well developed with 27 plumose marginal setae.

First maxilliped (Fig.4a) - Coxa and basal endites fused, showing 5 simple setae; endopod unsegmented with approximately 22 simple setae; exopod 2-segmented with 7 plumose setae on distal segment.

Second maxilliped (Fig.4b) - Basipod with 1 simple seta; exopod without segmentation and lacking setae; endopod 5segmented with 1,7,0,6,4 setae, respectively.

Third maxilliped (Fig.4c) - Basipod with 1 seta; exopod atrophied, lacking setae; endopod 5-segmented, with 10,9,7,9,5 setae, respectively.

\section{JUVENILE I}

Maxillule (Fig.3c) - Coxal endite with 19 marginal setae; basal endite with 11 marginal spines, $5+1$ plumose setae subterminal; endopod with 1 simple seta subterminal; propodite with 1 simple seta.

Maxilla (Fig.3d) - Coxal endite trilobed, with $20+10$ setae; proximal lobe with 6 setae; basal endite bilobed, with 11 setae in distal lobe and 5 in the proximal lobe; endopod with $1+3$ simple setae; scaphognathite well developed with 28 marginal plumose setae.

First maxilliped (Fig.4d) - Endopod unsegmented, with 28 simple setae; exopod unsegmented, bearing 15 distal plumose setae.

Second maxilliped (Fig.4e) - Exopod 2-segmented, with 2 terminal setae; endopod 5-segmented, with 3, 12, 0, 9, 6 setae, respectively.

Third maxilliped (Fig.4f) - Exopod 2-segmented, with 2 simple terminal setae; endopod 6-segmented, with 3 , $11,7,7,12,7$ setae, respectively.
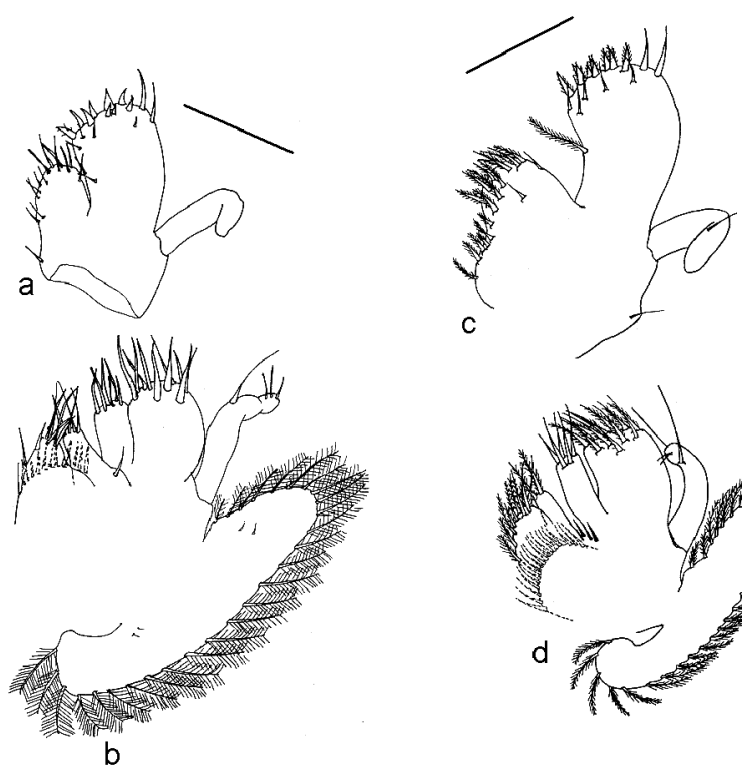

Figure 3 - Mouthparts of Lepidophtalmus siriboia, Felder \& Rodrigues, 1993. a-b Megalopa; c-d, juvenile I. a - maxillule; b - maxilla; $c$ - maxillule; $\mathrm{d}$ - maxilla. Scale bar: $a, b=0.08 \mathrm{~mm} ; c$ and $d=0.11 \mathrm{~mm}$. 


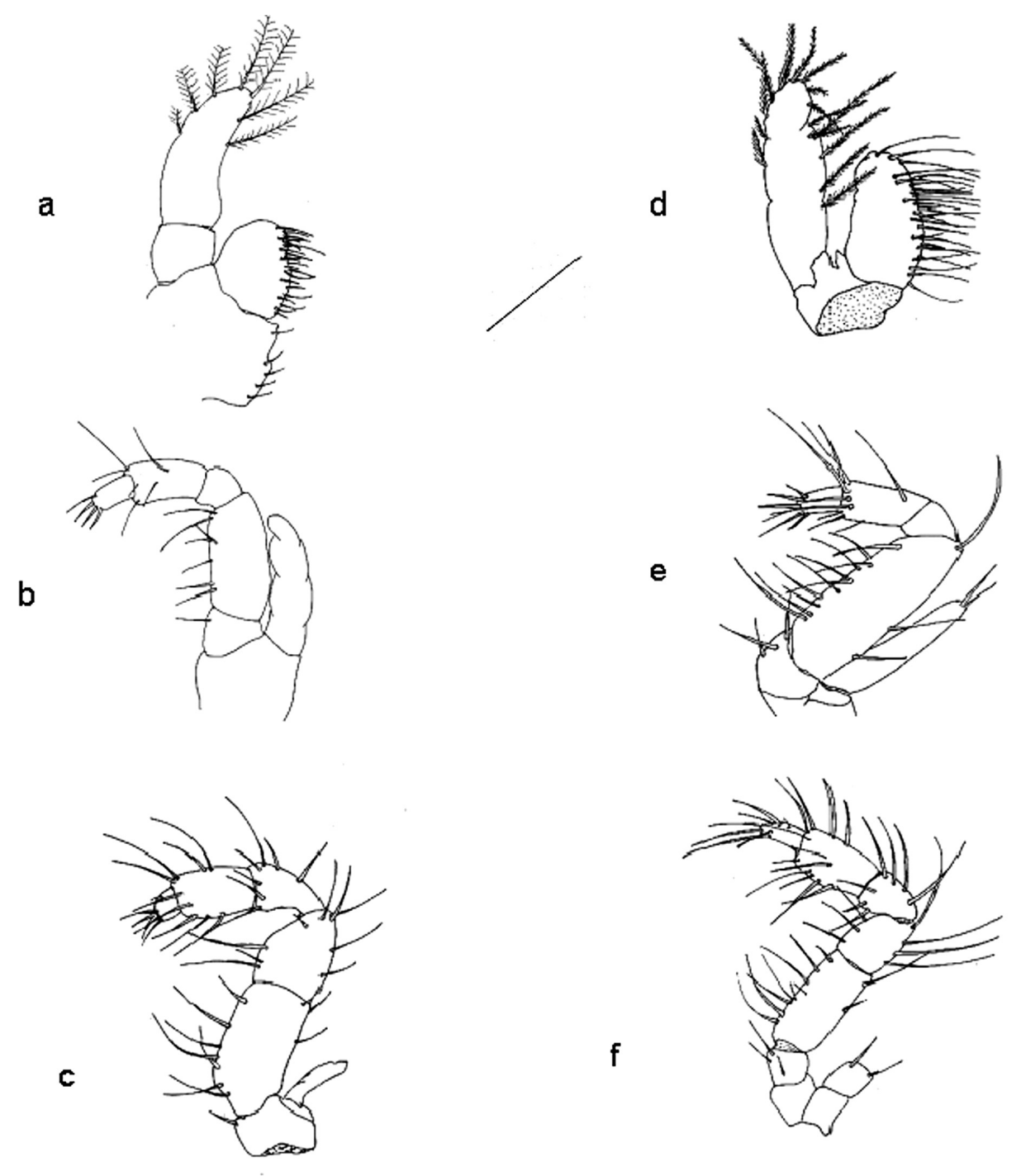

Figure 4 - Mouthparts of Lepidophtalmus siriboia, Felder \& Rodrigues, 1993: a-c, Megalopa; d-f, Juvenile I. a - Maxilliped I; b - Maxilliped II; c - Maxilliped III; d - Maxilliped I; e - Maxilliped II; $f$ - Maxilliped III. Scale bar: $0.3 \mathrm{~mm}$.

\section{MORPHOLOGY OF THE FOREGUTS}

\section{Zoea I (Fig.5a)}

Foregut with total length of $0.30 \mathrm{~mm}$, chitinous and lacking ossicles, showing a reduced number of scattered setae in the chambers. The cardiopyloric valve is present, unarmed and semicircular in shape.

Cardiac chamber - Shorter than pyloric chamber; cardiac floor lacking setae; cardiac wall bearing few minute setae.

Pyloric chamber - Pyloric roof with few scattered fine setae; filter press enlarged, filling all inferior portion of the pyloric chamber, structurally rudimentary and lacking setae, interampullary crista ridge and ampullary net poorly developed.

ZOEA II - Without noteworthy changes.

\section{Zoea III (Fig. 5b)}

Foregut with total length of $0.35 \mathrm{~mm}$, apparently more developed than zoea I, lacking ossicles or hard structures. The cardiopyloric valve is similar to the zoea I and zoea II foreguts.

Cardiac chamber - Little shorter than pyloric chamber, bearing several minute setae dorsally; cardiac floor lacking setae; main brush is present but little developed.

Pyloric chamber - Rectangularly shaped and enlarged than the cardiac chamber; rows of minute setae are present in the roof and in the posterior portion; filter press smaller but structurally more developed compared to the zoea I and II bearing a ampullary net completely formed but lacking interampullary setae. 
Foregut with total length of $0.4 \mathrm{~mm}$. Drastically changed compared to that of previous stage, bearing gastric mill with several ossicles. Pair of screw-shaped lateral tooth and a medial tooth is present; the cardiopyloric valve is shorter to that of zoeal stages, bearing numerous small setae on the dorsal edge.

Cardiac chamber - Enlarged dorsolaterally by the ossicles of the gastric mill; main and ventral brushes fully developed; the ossicles of the gastric mill are present i.e, zygocardiac (a pair, each bearing the lateral tooth), urocardiac (one, bearing the medial tooth), mesocardiac (a pair), pterocardiac (a pair), propyloric (one), exopyloric (a pair) and pyloric (one). The ossicles of the lateral ossicles are present as prepectinal (a pair), pectinal (a pair) and subdentate (a pair).

Pyloric chamber - Narrow laterally; with many setae on the roof and on the anterior and posterior portions of the pyloric chamber; some important ossicles are present, i.e., anterior and median pleuropyloric ossicles (a pair), uropyloric (one), posterior pleuropyloric (a pair); the lateral ossicles of the cardiopyloric valve and anterior supra ampullary are presents; the filter press shows a row of elongate setae on the interampullary ridge.

Juvenile I (Fig.7b)
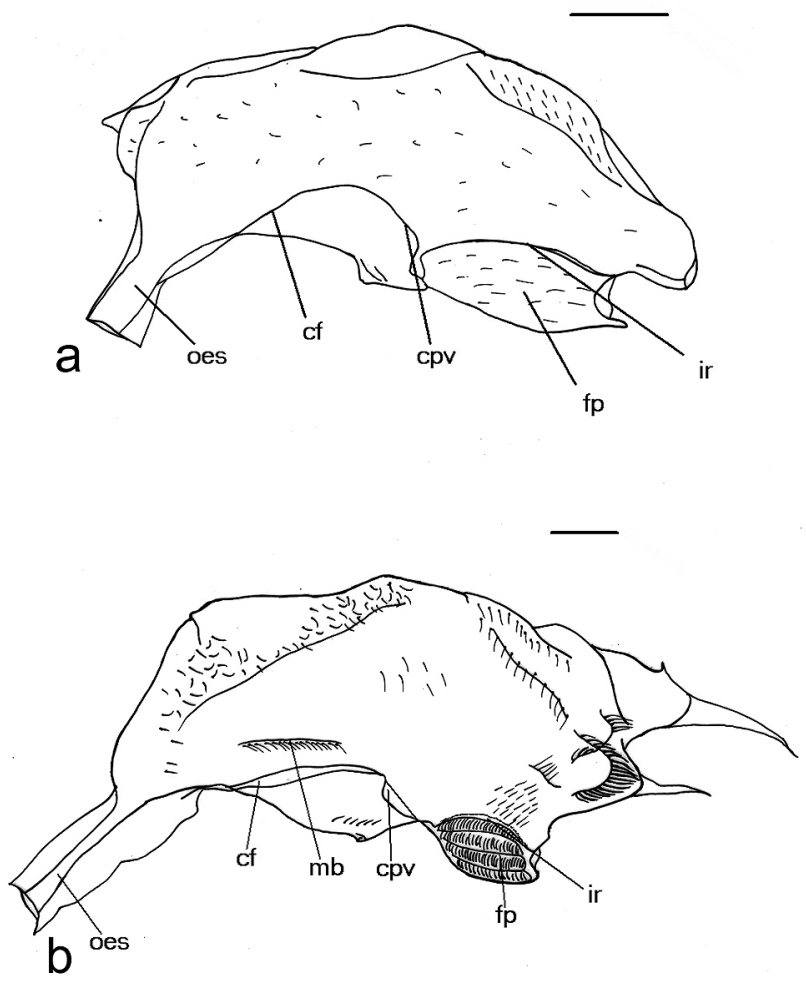

Figure 5 - Lepidophthalmus siriboia: a - foregut of zoea I, b - foregut of zoea III. Scale bar: $0.05 \mathrm{~mm}$. Abbreviations used are: $\mathrm{cpv}=$ cardiopyloric valve, $\mathrm{fp}$ $=$ filter press, ir $=$ interampullary ridge, $\mathrm{mb}=$ main brush, oes $=$ oesophagus.
Foregut with total length of $0.65 \mathrm{~mm}$. The juvenile foregut is complex compared to the megalopa stage. The gastric mill has ossicles heavily calcified, mainly on the cardiac chamber.

Cardiac chamber - Similar in shape to the megalopa stage; gastric mill is completely developed with ossicles articulated with the zygocardiac (bearing lateral teeth), urocardiac (bearing the medial tooth), mesocardiac, pterocardiac, propyloric, exopyloric and pyloric ossicle; other supporting lateral ossicles (prepectinal, pectinal and others) are present; cardiopyloric valve more specialized having specific setae on the superior portion.

Pyloric chamber - Narrow laterally with several setae in the roof and the anterior and posterior portions of the chamber; the anterior pleuropyloric, posterior mesopyloric, medial pleuropyloric, uropyloric, pleuropyloric, preampullary, anterior supraampullary ossicles are present; interampullary brush bearing a row of setae, ampullary net distinctly complex.

\section{DISCUSSION}

Examination of the zoea, megalopa and first juvenile mouthparts of L. siriboia indicates substantial morphological alteration during metamorphosis of the zoea to the megalopa stage. The absence of setae in the inner parts of the maxillule and maxilla and a reduced number of setae in the endopods of the first, second and third maxilliped indicates that these structures do not have feeding function.

In addition, few numbers of setae and absence of bristles in the cardiopyloric valve are observed in the zoeal foregut chambers. However, despite of a visible specialization of the filter press, few morphological changes occur during the development of the zoeal stomachs (Fig. 5a,b) compared to those zoeal stages previously reported (Abrunhosa et al., 2003; Melo et al. 2006; Lima et al., 2005). These observations strongly suggest that no functionality also occurs in the foregut during all zoeal development.

Anger et al. (1995) reported that larvae of Sesarma curacaoense are able to reach to the megalopa stage with entire absence of food. However, they have a facultative lecithotrophic development because they are feeding animals if foods are available in the environment. This observation was supported by Melo et al. (2006) who reported presence of numerous setae in the cardiopyloric valve and a complex and specialized filter press in the foreguts of $S$. curacaoense larvae.

A significant change occurs in the internal and external feeding structures of L. siriboia after the metamorphosis to the megalopa stage. The mouthpart appendages became substantially specialized with the presence of setae and spines in the endopods. Morphological modification also occurs in the internal structures of the stomach that show a calcified gastric mill with presence of lateral teeth and a medial tooth well developed suggesting that food is necessary for $L$. siriboia 

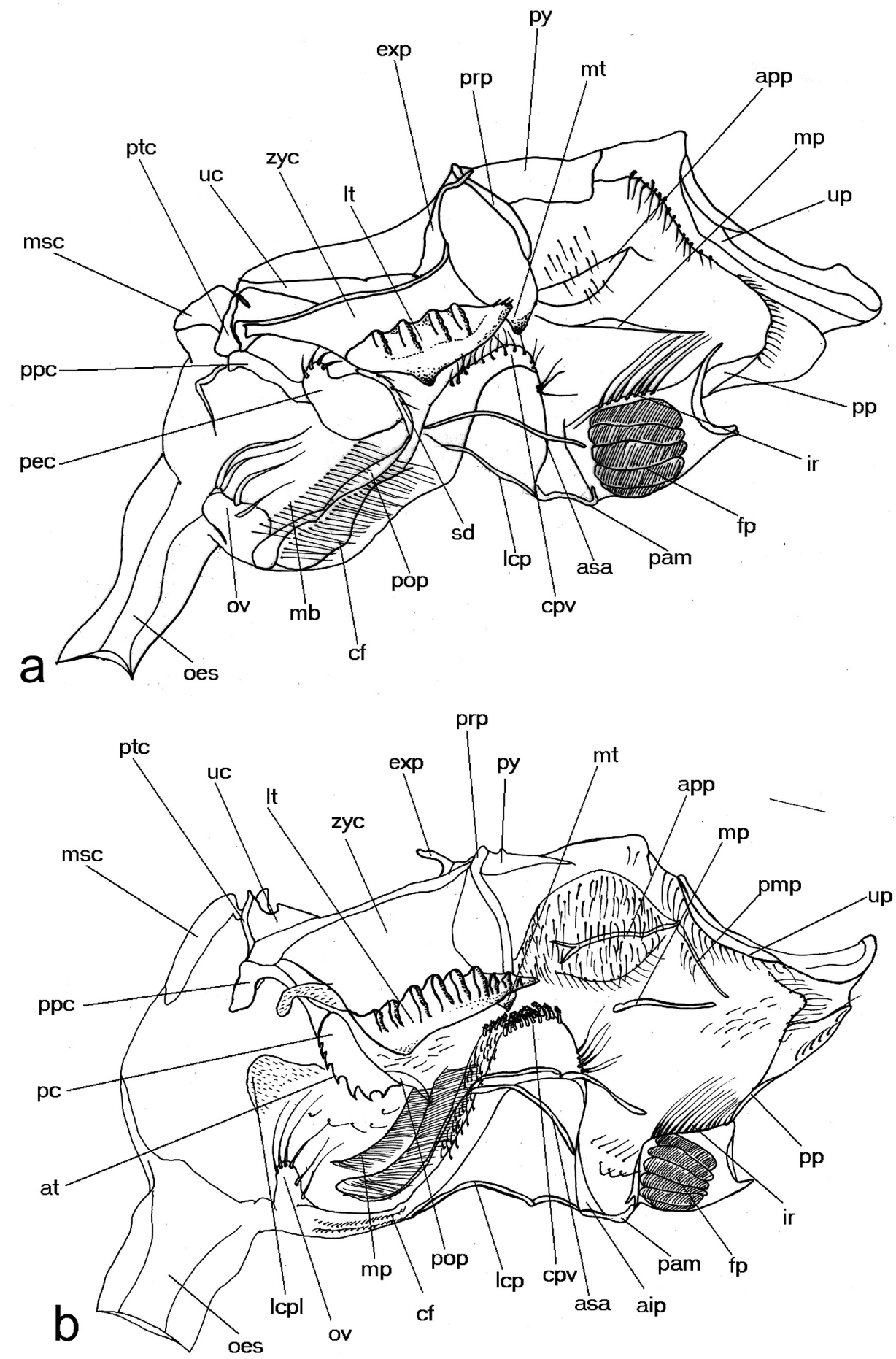

Figure 6 - Lepidophthalmus siriboia, Felder \& Rodrigues, 1993. a, foregut of megalopa; b, foregut of juvenile. Scale bar: $0.05 \mathrm{~mm}$. Abbreviations: aip = anterior inferior pyloric ossicle, app = anterior pleuropyloric ossicle, asa = anterior supra-ampullary ossicle, cf $=$ cardiac floor, $c p v=$ cardiopyloric valve, $\exp =$ exopyloric ossicle, $\mathrm{fp}=$ filter press, ilc $=$ inferior lateral cardiac ossicle, ia $=$ inferior ampullary ossicle, ir $=$ interampullary ridge, Icp $=$ lateral cardiopyloric ossicle, It = lateral teeth, $\mathrm{mb}=$ main brush, $\mathrm{mp}=$ median pleuropyloric ossicle, $\mathrm{msc}=$ mesocardiac ossicle, oes = oesophagus, ov = oesophageal valve, pam $=$ preampullary ossicle, pec $=$ pectinal ossicle, pip $=$ posterior inferior pyloric ossicle, pmp $=$ posterior mesopyloric ossicle, pop $=$ postpectinal ossicle, $\mathrm{pp}=$ posterior pleuropyloric ossicle, $\mathrm{ppc}=$ prepectinal ossicle, prp $=$ propyloric ossicle, ptc $=$ pterocardiac ossicle, py $=$ pyloric ossicle, $\mathrm{sd}=$ subdentate ossicle, up $=$ uropyloric ossicle, urc $=$ urocardiac ossicle and zyc $=$ zygocardiac ossicle. 
megalopa and they are adapted to ingesting great amounts of food.

Nishida et al. (1990) reported puerulus of lobster Jasus edwardsii with atrophied or entire absence of bristles and spines in the maxillae and an uncalcified and poorly developed foregut. Abrunhosa and Kittaka (1997a) verified a similar fact in these structures for glaucothoe (megalopa) of king crab species Paralithodes camtschaticus, P. brevipes and P. platypus. On the other hand, feeding behavior is observed in the megalopae of brachyuran in a recent study with Ucides cordatus (Abrunhosa et al., 2003) in which the megalopae presented high alimentary activity.

The morphology of the feeding structures showed the juvenile more developed compared to the megalopa. The mouthparts of the juvenile I present increasing setae numbers in the endopods. The juvenile stomach became more calcified and visibly complex, with similar characteristics to those found in the foregut of adult decapods described in the scientific literature (Meiss and Norman, 1977; Kunze and Anderson, 1979: Suthers and Anderson, 1981; Mikami and Takashima, 1993; Brösing $e t$ al. 2002). This indicates that juvenile of $L$. siriboia became more agile in food capture and they are capable to process solid food available in their bentonic ambient.

\section{LITERATURE CITED}

Abrunhosa, F.A.; Kittaka, J. 1997a. Functional morphology of mouthparts and foregut of the last zoea, glaucothoe and first juvenile of the king crabs Paralithodes camtschaticus, P. brevipes and P. platypus. Fisheries Science, 63(6): 923-930.

Abrunhosa, F.A.; Kittaka, J. 1997b. Morphological changes in the midgut, midgut gland and hindgut during the larval and postlarval development of the red king crab Paralithodes camtschaticus. Fisheries Science, 65(5): 746-754.

Abrunhosa, F.A.; Melo, M.A.; Abrunhosa, J.P. 2003. Development and functional morphology of the foregut of larvae and postlarva of Ucides cordatus (Decapoda, Ocypodidae). Nauplius, 11(1): $37-43$.

Abrunhosa, F. A.; Pires, M. A. B.; Lima, J. F.; Coelho-Filho, P. A. (2005). Larval development of Lepidophtalmus siriboia Felder \& Rodrigues, 1993 (Decapoda: Thalassinidea) from the Amazon region, reared in the laboratory. Acta Amazonica, 35(1): 77-84.

Anger, K.; Schreiber, D.; Montú, M. 1995. Abbreviated larval development of Sesarma curacaoense (Rathbun, 1897) (Decapoda: Grapsidae) reared in the laboratory. Nauplius, 3: 127-154.
Brösing, A.; Richter, S.; Scholtz, G. 2002. The foregut-ossicle system of Dromia wilsoni, Dromia personata and Lauridromia intermedia (Decapoda, Brachyura, Dromiidae), studied with a new staining method. Arthropod Structure \& Development, 30: 329-338.

Kittaka, J. 1988. Culture of the palinurid Jasus lalandii from egg to puerulus. Nippon Suisan Gakkaishi, 54(1): 87-93.

Kittaka, J. 1994. Larval rearing. In: Phillips, B.F.; Cobb, J.S.; Kittaka, J. (Eds.). Spiny lobster management. Oxford: Fishing news book, UK p. 402-423.

Kunze, J.; Anderson, D.T. 1979. Functional morphology of the mouthparts and gastric mill in the hermit crabs Clibanarius taeniatus (Milne Edwards), Clibanarius virescens (Krauss), Paguristes squamosus McCulloch and Dardanus setifer (Milne Edwards) (Anomura: Paguridae). Australian Journal of Marine Freshwater Research, 30(5): 683-722.

Lemmens, J.W.T.J.; Knott, B. 1994. Morphological changes in external and internal feeding structures during the transition phyllosoma-puerulus-juvenile in the western rock lobster (Panulirus cygnus: Decapoda: Palinuridae). Journal of Morphology, 220(3): 271-280.

Lima, J. F.; Abrunhosa, F. A.; Melo, M. A. 2005. Development and functional morphology of the foregut of the larval and post larval stages of Petrolisthes armatus (Gibbes, 1850) (Decapoda, Porcellanidae) reared in laboratory. Revista Ciência Agronômica. 35(3): $290-294$

Meiss, D.E.; Norman, R.S. 1977. Comparative study of stomatogastric system of several decapod Crustacea. I. Skeleton. Journal of Morphology, 152(1): 21-53.

Melo, M. A.; Abrunhosa, F. A.; Sampaio, I. 2006. The morphology of the foregut of larvae and post-larvae of Sesarma curacaoense De Man, 1892: a species with facultative lecithotrophy during larval development. Acta Amazonica. (in press).

Mikami, S.; Takashima, F. 1993. Functional morphology of the digestive system. In: Phillips, B.F.; Cobb, J.S.; Kittaka, J. (Eds.). Spiny lobster management. Oxford: Fishing news book, UK. p. 473-482.

Nates, S. F. \& MckenneyJr, C. L. 2000. Ontogenic changes in biochemical composition during larval and early postlarval development of Lepidophthalmus louisianensis, a ghost shrimp with abbreviated development. Comparative Biochemistry and Physiology, part b: Biochemistry and Molecular Biology, 127(4): 459-468.

Nishida, S.; Quigley, B.D.; Booth, J.D.; Nemoto, T.; Kittaka, J. 1990. Comparative morphology of the mouthparts and foregut of the final-stage phyllosoma, puerulus, and postpuerulus of the rock lobster Jasus edwardsii (Decapoda: Palinuridae). Journal of Crustacean Biology, 10(2): 293-305. 


\section{ACTA
AMAZONICA}

DEVELOPMENTAL MORPHOLOGY OF MOUTHPARTS AND FOREGUT OF THE LARVAE AND POSTLARVAE OF Lepidophthalmus siriboia FELDER \& RODRIGUES, 1993 (DECAPODA: CALLIANASSIDAE)

Nishida, S.; Takahashi, Y.; Kittaka, J. 1995. Structural changes in the hepatopancreas of the rock lobster Jasus edwardsii (Crustacea: Palinuridae) during development from the puerulus to postpuerulus. Marine Biology, 123(4): 837-844.

Suthers, I.M.; Anderson, D.T. 1981. Functional morphology of mouthparts and gastric mill of Ibacus peronii (Leach) (Palinura: Scyllaridae). Australian Journal of Marine Freshwater Research, 32: 931-944.

Thessalou-Legaki, M., Peppa, A. \& Zacharaki. 1999. Facultative lecithotrophy during larval development of the burrowing shrimp Callianassa tyrrhena (Decapoda: Callianassidae). Marine Biology, 133: 635-642.
Wolfe, S. H. \& Felgenhauer, B. E. 1991. Mouthpart and foregut ontogeny in larval, post larval, and juvenile spiny lobster, Panulirus argus Latreille (Decapoda: Palinuridae). Zoologica Scripta, 20: 57-75.

Recebido em 03/06/2005

Aceito em 07/07/2006 